\title{
4
}

\section{CENTRALISED AND DECENTRALISED DEPLOYMENT MODELS}

\section{Is small beautiful?}

\author{
Ulrich Elmer Hansen, Cecilia Gregersen, Faith $\mathrm{H}$. \\ Wandera, Nina Kotschenreuther, and Rebecca Hanlin
}

\begin{abstract}
The sectoral innovation system perspective has been developed as an analytical framework to analyse and understand innovation dynamics within and across various sectors. Most of the research conducted on sectoral innovation systems has focused on an aggregate-level analysis of entire sectors. This chapter argues that a disaggregated (sub-sectoral) focus is more suited to policy-oriented work on the development and diffusion of renewable energy, particularly in countries with rapidly developing energy systems and open technology choices. Based on preliminary insights from research carried out in 2016 and 2017, including mapping, interviews, and policy framework analysis, it focuses on size, distinguishing between small-scale (minigrids) and large-scale (grid-connected) deployment paths in renewable energy. We explore how wind and solar markets in Kenya differ in terms of development and organisation, both across and within sectors, by examining the development and diffusion of solar photovoltaic (PV) and wind technology and how they evolve in these sub-sectoral systems. We find that innovation and diffusion dynamics differ more between small and large than between wind and solar. This has important analytical implications because the disaggregated perspective allows us to identify trajectories that cut across conventionally defined core technologies. This is valuable for ongoing discussions of electrification pathways in developing countries. We conclude the chapter by distilling the policy implications of these findings in terms of the requirements and incentive mechanisms that shape different pathways.
\end{abstract}

\section{Introduction}

Kenya, like many other countries around the globe, is currently facing momentous energy decisions. With a low rural electrification rate and a large proportion 
of the population currently lacking access to electricity, increasing generating capacity and achieving 100\% energy access is a key priority for the Kenyan government. While the current electricity system relies mainly on hydropower, the expansion of renewable energy (RE) sources, especially wind and solar power, has been given a high priority in national policies such as the national development strategy Vision 2030 and the rural electrification master plan (GoK, 2007; REA, 2009). In this context, Kenya faces a number of important technological choices in terms not only of which technologies to prioritise, but also how to deploy them. The current policy frameworks have enabled a combination of government and private-sector developments in the energy sector (See Ogeya et al., 2022; this volume, and Kingiri and Okemwa, 2022; this volume).

The concept of sectoral innovation systems (SIS) has been used to illuminate the factors affecting innovation dynamics within and across sectors. The SIS perspective is particularly concerned with highlighting sector-specific characteristics of industrial evolution (Malerba and Nelson, 2011). From the sectoral perspective, increasing attention is paid to RE sectors and their development. In this chapter, we argue that it is crucial to take a closer look at the RE sector and what constitutes such a sector in order to push further the disaggregation of trends in the sub-sectors of wind and solar PV. In examining differences in terms of size and shape across and between these sub-sectors, we raise questions regarding the definitions and boundaries of these renewable energy 'sectors'.

Thus, the key research question of this chapter is: how do wind and solar markets in Kenya differ in terms of development and organisation, both across and within sectors? We answer this question by analysing current status and developments across the mini-grid and large-scale market segments for wind and solar PV technologies, respectively. Then we use the SIS perspective to describe the characteristics of each sub-sector, their drivers, and barriers, and discuss the similarities and differences between them. As detailed and up to date information on the development and dynamics of the solar and wind markets in Kenya were found to be lacking, this chapter seeks to bring together insights from research conducted in 2015-2016.

The chapter is structured as follows: we start by briefly introducing the disaggregated sectoral innovation systems approach and the methodology. Then we present an overview of the current status and trends across the mini-grid and large-scale market segments for wind and solar PV in Kenya. ${ }^{1}$ Next, we describe each of the four disaggregated sectoral innovation systems and their characteristics followed by a discussion of the similarities and differences across these sectors using the three main dimensions of the SIS approach as vectors. Finally, we offer concluding remarks on sub-sectoral pathways and policy implications based on the key findings of the research.

\section{The disaggregated SIS perspective and methodology}

Innovation systems approaches are increasingly used for the analysis of development challenges in Africa (Adebowale et al., 2014; Lundvall and Lema, 2014). 
The sectoral systems perspective ascribes importance to learning, knowledge, and capability accumulation in the innovation process (Malerba, 2005). The SIS perspective is based on the underlying assumption that innovation dynamics are closely related to the specific characteristics of a given sector or industry. Innovation within a sector is a dynamic process, which constantly transforms the structure and boundaries of a given industry.

In this chapter, the focus is on analysing two low carbon technologies, namely solar PV, and wind technologies in Kenya. While there are profound differences between low carbon technologies (Lema et al., 2015), the differences within solar PV and wind energy as overarching technological categories are equally profound. To give an example, the notion of a 'solar technology' may be used as an umbrella term to describe solar-powered LED lamps, solar home systems, and utility-scale solar power plants. Common to these systems is the fact that they make use of solar panels as the underlying source of electricity generation. However, it is clear that there are significant differences between the respective users, producers, investors, actors, prices, scales, R\&D intensities, value chains, technical characteristics, and competing technologies of these systems (Adebowale et al., 2014). As noted by Stephan et al. (2017), understanding such differences in sectoral configurations helps identify dynamics that otherwise go unnoticed. As a result, each of the sub-categories of these systems of technology may more appropriately be considered units of analysis in their own right. In the delineation of specific sectors, a key question therefore concerns the selection of an appropriate level of aggregation in the analysis.

Initially, Malerba defined SISs broadly as 'a set of new and established products for specific uses and the set of agents carrying out market and non-market interactions for the creation, production and sale of those products' (Malerba, 2002 , p. 250). While this broad definition was developed with the intention to be able to cover research conducted at various levels of aggregation, most empirical studies in this field focus on a highly aggregated level of analysis covering the entire pharmaceutical, chemical, telecommunications, or biotechnology sectors (Malerba, 2005). In this chapter, we adopt a more disaggregated level of analysis in order to uncover in further detail the innovation dynamics within such overarching and broadly defined sectors.

Accordingly, the cases of solar and wind technologies examined in this chapter are understood as sub-sectors of the wider renewable energy sector, which in turn is considered a subset of the broader energy sector, and so forth. Based on this understanding, we distinguish between small-scale mini-grids and large-scale power plants using solar and wind technologies to generate electricity. Mini-grids are understood as decentralised (off-grid) systems consisting of power-generating assets and distribution with power capacities of between $0.2 \mathrm{~kW}$ and $2 \mathrm{MW}$ connecting two or more individual households (Pedersen, 2016). Large-scale power plants are understood as grid-connected plants owned by utilities and/or private operators with installed capacities above $15 \mathrm{MW}$. 
The above description translates into the conceptualisation of four different SISs in Kenya with distinctive sector-specific innovation features, which are explored in the chapter: (i) wind-powered mini-grids; (ii) large-scale, grid-connected wind-power plants; (iii) solar-powered mini-grids; and (iv) large-scale, grid-connected solar power plants. Following the SIS perspective, three main dimensions are used to guide the analysis of these four sectors (Malerba and Nelson, 2011):

- Knowledge and technologies

- Actors and networks

- Institutions

\section{Overview of current status and trends across the mini-grid and large-scale market segments for wind and solar PV in Kenya}

The analysis is based on research presented in Hansen et al. (2018). This article was based on insights from research conducted in 2016 and 2017 as part of the wider project on renewable electrification in Kenya entitled Innovation and Renewable Electrification in Kenya (IREK), which examines the implementation of wind and solar technologies in Kenya's renewable electrification process (IREK, 2018).

Table 4.1 presents a summary of the findings from Hansen et al. (2018). The main source of information was semi-structured interviews carried out in Nairobi in 2016 and 2017 with key actors involved in the sectoral systems. Actors and organisations interviewed include project developers, regulators, investors, plant operators, technology suppliers, donor agencies, and government agencies. To gain an overview of the market status and trends and to triangulate information, desk research reviewed and consulted a large variety of documents, including papers from the peer-reviewed literature, media reports, presentations, company press releases, and industry and other reports.

Looking at the overall wind sector, there is clear variation in the dynamics of small- and large-scale wind. The market for small-scale wind-based mini-grids appears to have stalled: very few hybrids exist or are planned, and private suppliers of wind-powered mini-grids have shifted focus (see also Wandera, this volume). In contrast, the market for large-scale wind projects is moving forward, with the flagship Lake Turkana project (see Gregersen and Gregersen, 2022; this volume) drawing massive attention, together with a number of other large-scale projects.

In the overall solar sector, the market for small-scale solar-based mini-grids is currently experiencing a period of significant momentum, with both private mini-grid operators and many donors involved with existing and planned hybrid greenfield mini-grids (Duby and Engelmeier, 2017). On the other hand, the market for large-scale solar projects has only moved to a very limited extent on 
TABLE 4.1 Summary of current status and trends across sectors

Small Wind-powered mini-grids

- State-owned mini-grids include two operational wind hybrids owned by REA

- Five KPLC diesel mini-grids are being retrofitted to include wind power

- Scarce information regarding commercial wind- and solarpowered mini-grids indicate 80-100 small wind turbines installed by telecom players, NGO's, and commercial and household clients

- Local manufacturer active since late 1990s, three foreign suppliers active since 2010 , however focus and activities have shifted towards the emerging market for solar mini-grids

- Approx. 20 companies currently offer imported turbines, but mainly as complement to their main product, solar PV

- 19 wind-diesel hybrids planned as part of the implementation of the Kenyan government's rural electrification master plan 2009

- One donor-funded project (UNIDO) implemented in 2009

\section{Large Grid-connected wind-power} plants

- Two operational plants, Ngong Power Station, owned by KenGen (establ. 1993), and the independently owned Lake Turkana Wind Power project

- Two projects under development, (while one other project was cancelled at a late stage), all being developed in connection with the Kenyan Feed-in Tariff for wind-power project (FIT, first introduced in 2008 , revised in 2012) by different consortiums with international actors

\section{Solar-powered mini-grids}

- State-owned mini-grids include seven solar-diesel hybrids and one windsolar-diesel hybrid, owned by REA, operated by KPLC

- A further 15 state-owned mini-grids including solar power currently under construction

- One local solar PV assembly plant and a number of local battery producers/ suppliers, but they mainly serve the domestic solar market

- Nine hybrid solar-diesel stations being developed (in existing diesel-fired plants) and an additional 25 in initial proposal stage

- Donor organisations actively promote and financially support a number of specific projects

- Since 2012 a number of private foreign-owned companies have installed 20-30 grids (two of these with a formal licence to operate) and are in the process of significantly upscaling their activities

- Most core components are sourced from renowned suppliers from Europe or the United States

\section{Grid-connected solar power plants}

- Five plants $(<575 \mathrm{kWp})$ currently in operation, three financed mainly by international donors, two by private firms. Seven plants above $15 \mathrm{MW}$ are planned/ under development

- Delivered on turnkey basis from suppliers abroad

- Involvement of local companies is limited to the construction stage and maintenance services during operation 
TABLE 4.1 (Continued)

- Private developers, donors, and development banks have provided financial support and advisory services to move the Kenyan Feed-in Tariff for wind-power project to financial closure

- By 2013 a total of 236 applications were submitted under the FIT project, of which 20 were approved. However, a freeze on new power purchase agreements for wind and solar projects means that their development is uncertain
- One large-scale project (Garissa, owned by REA) is in operation, while a number of other larger scale projects developed by foreign suppliers seem to be under development (since 2012), most of which are supported by donors and development banks, but are struggling to secure funding and reach financial closure, hence most have not yet reached construction

Source: Hansen et al. (2018).

the ground, as existing projects are small in scale, and many large-scale projects remain at the planning stage. In the next section, these trends will be compared to the characteristics of the four disaggregated SISs.

\section{The size and shape of wind and solar sectoral innovation systems}

In the following section, the characteristics of the four SISs are explored and disentangled. The SIS perspective is used to describe the three dimensions knowledge and technologies; actors and networks; and institutions - of the wind and solar sectors across the size and shape of the projects.

\section{Sectoral innovation system characteristics of wind-powered mini-grids}

The existing knowledge and technological base in the domestic industry for wind powered mini-grids in Kenya is characterised by relatively simple and small-scale technologies manufactured locally. Such small-scale systems can be tailored to different local contexts and manufactured from a range of locally available materials while still being relatively robust. As the turbines are typically produced by smaller manufacturers, universities, or NGOs involved in community projects, they do not require advanced engineering knowledge or skills. Thus, as opposed to formalised R\&D, the domestic industry for small-scale wind turbines is generally characterised by a high level of informal knowledge and learning in the way that local artisans and blacksmiths tinker with various designs based on the available equipment and materials. While the wind turbines are produced and diffused at relatively low cost, final performance and standards tend to vary greatly. The 
locally produced systems are contrasted with the imported turbines used in the existing wind-diesel hybrid mini-grids, which are generally higher in performance and price levels (Vanheule, 2012). Due to the lack of experimentation with wind-powered mini-grids, related technical concepts, and commercial applications, limited specialisation and experience has been accumulated in this area.

The main supportive institutional conditions promoting the development of wind-powered mini-grids are related to initiatives adopted as part of the rural electrification master plan to hybridise the existing diesel-fired mini-grids with wind and solar (REA, 2009). These initiatives are supported and complemented by various donor programmes but are also driven by the increasing operational costs of the existing diesel-fired mini-grids. The main actors involved in the domestic industry are local wind-turbine manufacturers, NGOs, and local community entrepreneurs involved in various small-scale projects typically implemented by donors in rural villages (Harries, 1997; Bergès, 2009). A number of these projects include individual engineers and NGOs from abroad, involved in testing a specific technical design for rural applications, however with limited levels of commercialisation (Ferrer-Martí et al., 2012). The local manufacturers rely on local supply chains and distribution networks and typically make use of connections in the local environment for sourcing materials and related knowhow. Government agencies promoting rural electrification in off-grid areas are typically also involved in specific projects either directly or indirectly via technical support. The Ministry of Energy and Petroleum is involved in the installation of wind speed data loggers at $20 \mathrm{~m}$ and $40 \mathrm{~m}$. Local universities sometimes provide highly applied research input to specific projects such as a collaboration between Jomo Kenyatta University of Agriculture and Technology and the Japanese Government on small wind technology, but formalised R\&D activities at universities focusing specifically on small scale wind is largely absent in Kenya.

\section{Sectoral innovation system characteristics of large- scale, grid-connected wind power projects}

The knowledge and technology base underlying the development of advanced large-scale wind turbines has evolved into a highly researched and capital-intensive process involving the continuous development of new materials, designs, and production methods. Thus, the development of utility-scale wind turbines involves both internal R\&D carried out within industry lead firms and formalised R\&D undertaken by research centres at universities or public research organisations. These R\&D activities mainly draw on technical disciplines and engineering-based knowledge. The ongoing development efforts focus on reducing the price and improving the performance of wind turbines in order to increase the competitiveness of wind power compared to conventional sources of energy for power generation. As economic feasibility generally increases with the size of the wind turbines, the general trend in the industry has been towards the gradually increasing scale of wind turbines. The development of large-scale 
wind-power projects also draws on a broader set of organisational and administrative competences, including the skills and systems for turbine component manufacturing (e.g., supply chain management) and the knowledge required for engineering, procurement, and construction (EPC) contracting and the incorporation of third-party consultants (legal advice and engineering consultancy). In the projects under development in Kenya, the main contractors and windturbine suppliers have drawn upon a range of such knowledge bases and areas of expertise during project development.

International actors, such as pension funds, development banks, donors, and other types of financial institutions, play an important role in providing finance for the development of the projects. Due to the high national relevance of the projects as large infrastructure investments, national policy makers, regulatory bodies, and government agencies are also involved in developing them.

The government support for large-scale wind (and solar) is part of a broader objective to attract foreign investment in Kenya by making possible the inclusion of private, independent power producers (IPPs) in the energy sector. While direct involvement includes bilateral negotiations between project developers and the relevant authorities, indirect involvement includes political advocacy influencing the projects. While not being directly involved, local community and actor groups exert a strong indirect influence on project development, mainly due to disagreements over land rights issues. The main supporting instrument promoting the development of large-scale wind-power plants in Kenya is the feed-in tariff, which has undergone several revisions and currently has $50 \mathrm{MW}$ cap for projects.

\section{Sectoral innovation system characteristics of solar-powered mini-grids}

The knowledge base underlying the development of solar-powered mini-grids in Kenya draws on a variety of disciplines and relies particularly on foreign expertise. In the case of the state-owned solar-diesel hybrids, the main expertise needed is in the area of turnkey contracting. The necessary technological skills of the total system suppliers relate mainly to the capacity to design the plants, manage the sourcing of key components, and undertake the construction and final commissioning of the plants. Since this expertise is not currently available from domestic suppliers in Kenya, European companies with significant experience in turnkey contracting and related engineering tasks dominate the development of these plants. Despite the technical capacity and knowledge accumulated in the domestic industry for solar home systems (Byrne, 2011; Karjalainen and Byrne, 2022; this volume), the local suppliers of core components (such as panels and batteries) seem disconnected from the development of solar-powered mini-grids. The private companies from abroad supplying solar-powered mini-grids on a commercial basis in Kenya draw mainly on engineering-based knowledge in the ongoing technical experimentation efforts to optimise their mini-grid systems. Experience from the 
telecommunications industry has also provided input into the development of business models based on pay-as-you-go (PAYG) systems specifically developed to target poor customers in rural, off-grid areas. This business model draws on knowledge about IT and software solutions and related data analysis and optimisation systems, as well as the use of smart metering and monitoring technologies. Some of these companies are engaged in client relations with (private) investors in solar-powered mini-grids, some of which are philanthropic foreign investors (Harrington, 2016). Collaborative networks have been established across a number of these companies, as well as linkages to foreign investors, headquarters, and component suppliers in Europe and the United States. A number of state and donor-funded programmes to hybridise the existing diesel-fired mini-grids are greatly influencing the enabling environment for the development of solar-powered mini-grids in Kenya.

However, the existing regulatory framework for rural electrification, which focuses on conventional grid-extension programmes, continues to play an important role in the development of commercial solar-powered mini-grids, resulting in lengthy approval and negotiating processes for project developers. ${ }^{2}$ Challenges faced by many solar mini-grid developers still often include access to finance or ensuring affordability of the projects, as the higher cost of such small-scale energy production is borne by the consumers. The lack of focus on such new models for producing and distributing energy is also visible in the policy frameworks, where grid-owners and operators have called for stronger and clearer regulation regarding tariffs, integration, standards, and licensing, as well as the possibility for subsidy schemes (Duby and Engelmeier, 2017).

\section{Sectoral innovation system characteristics of large- scale, grid-connected solar power projects}

A key driver for the development of large-scale solar power plants in Kenya is the rapidly decreasing costs of solar panels. The experience of plants under development in Kenya indicates that designs for large-scale solar power plants are generally well proven globally, requiring only minor design and construction modifications to adapt them to local conditions. The knowledge and technological base underlying the development of large-scale solar power plants in Kenya thus draws greatly on foreign expertise in the delivery of plants on a turnkey basis. European companies with substantial experience in turnkey plant engineering, component sourcing, and commissioning have thus delivered the existing plants in cooperation with locally based consultancy companies. Due to the larger scale of the solar power plants currently under development in Kenya, their development draws on additional knowledge of EPC contracting and the related organisational expertise to manage the development of large infrastructure projects. Consequently, international contractors and technology suppliers with the technical expertise and management skills to develop an integrated plant design and to install and operate the system effectively have been involved 
in planning and developing the projects, as well as providing additional competences in the area of PPA contract negotiations, the legal aspects and detailed engineering tasks.

While development of the existing solar power plants has included industrial users and donors as the project owners, the larger scale solar power plants under development incorporate direct involvement from international investors, including development banks and donor organisations. However, the development of large-scale solar is generally being prevented by the difficulties project developers face in attracting finance from foreign investors, and concerns have been raised that the feed-in tariff system may be too low to incentivise foreign investments significantly (Hansen et al., 2015).

\section{Discussion: sub-sectoral dynamics across size and shape}

Distinguishing sectoral innovation system features across market segments and technologies has shown that it is worth considering the similarities and differences between the size and shape of the different sub-sectors of solar PV and wind energy in Kenya. In the following sections the three dimensions of Malerba's (2005) SIS framework are examined across the four sub-sectors (see Table 4.2).

\section{Differences and similarities between knowledge and technology}

Regarding the knowledge dimension, it is clear that both within and across the four SISs, each system is characterised by individually distinct knowledge bases. In fact, as noted by Malerba (2005), it is knowledge and technology that place the issue of sectoral boundaries at the centre of analysis. These differences therefore support the argument that a disaggregated sectoral analysis is necessary, perhaps particularly in respect of SIS size (Stephan et al., 2017). This is evident in that both large-scale wind and large-scale solar share some characteristics related to the size of the project, where EPC contractors and turnkey suppliers are present across the technologies. Many of the enabling aspects of this dimension are found in the intersections with the global sectoral characteristics where international actors have established themselves in the Kenyan market. This is notable because domestic actors seem disconnected, despite the technical capacity and knowledge that have been accumulated particularly in the domestic industry for solar home systems. There is little information on the involvement of local suppliers of either solar or wind components in any project. It is noteworthy, however, that across the solar and wind mini-grid sectors the knowledge base dimensions differ in terms of which actors with which knowledge bases are involved. While informal learning and knowledge characterise the wind mini-grid sector, the solar mini grid sector features rather engineering-based knowledge, with more involvement from both private actors and international donors. The solar-powered mini-grid sector is also highly 


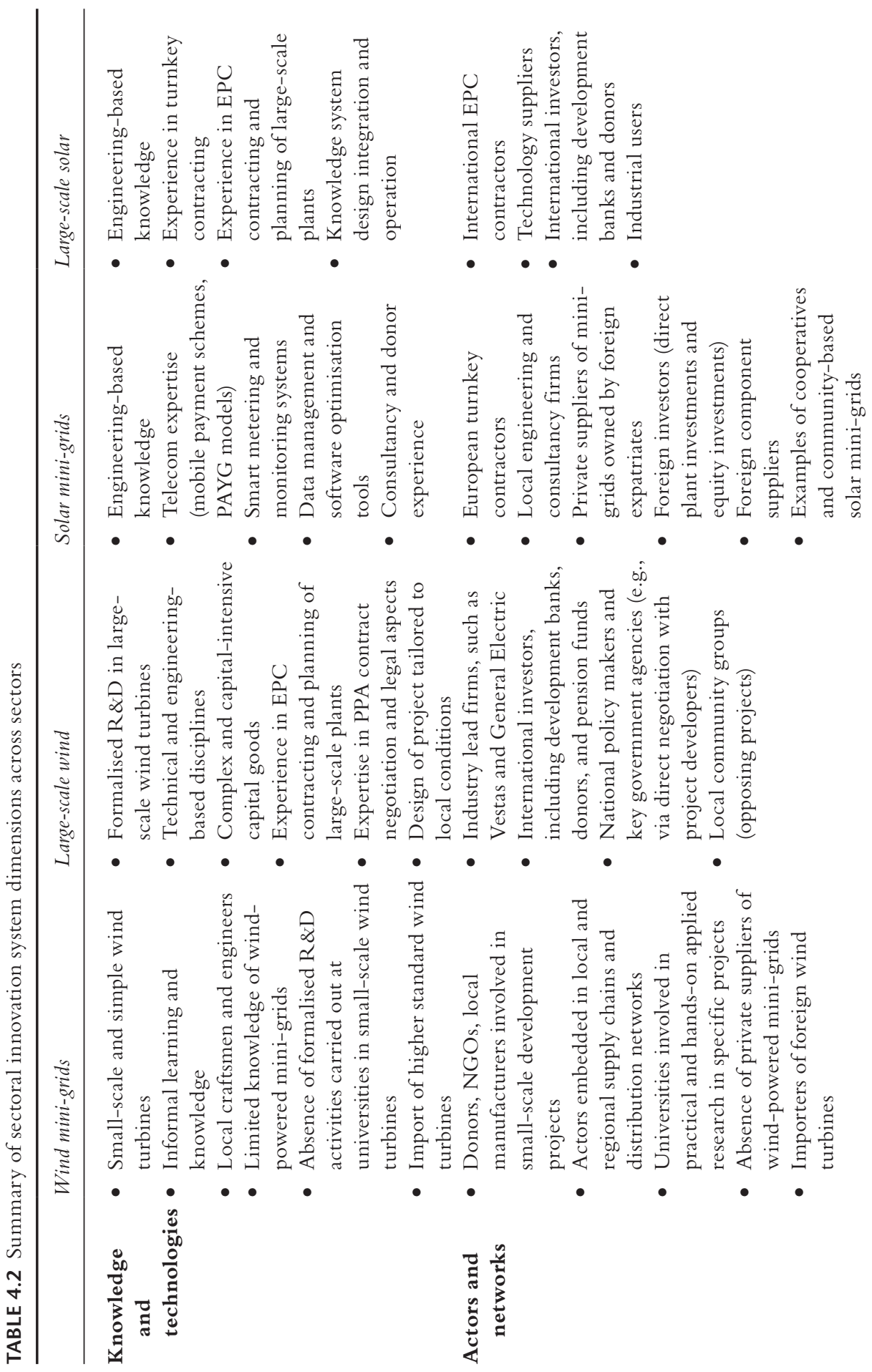


82 Ulrich Elmer Hansen et al.
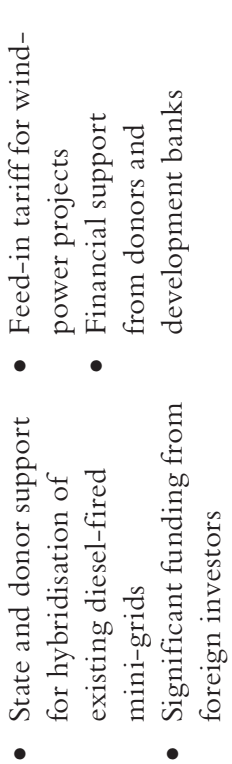

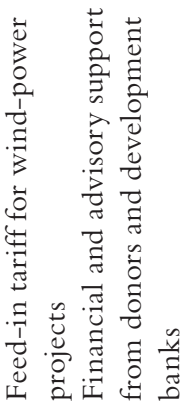

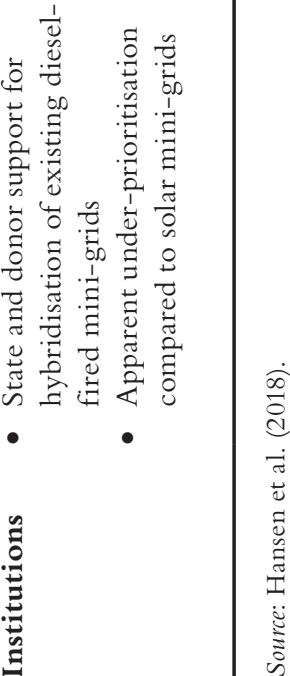


specialised, with business models and software catering to specific PAYG customer segments.

\section{Differences and similarities between actors and networks}

In the actor dimension, foreign industry actors play a role across large-scale wind, large-scale solar, and solar mini-grids. However, in wind mini-grids there is no significant presence of foreign industry actors; rather, small-scale domestic industry actors and foreign actors such as NGOs and donors focusing on small-scale development projects are dominant. While there are universities involved in practical and hands-on applied research in scientific projects, this does not translate into organised R\&D in the domestic industry, and there is a notable absence of private suppliers of wind-powered mini-grids in the sector. In the solar mini-grid sector there are a number of private suppliers, foreign investors, and foreign component suppliers, as well as turnkey contractors. Across both large-scale wind and solar power projects, the role of lead firms in the global industry in the wind sector and international EPC contractors is clear.

The role of local community actors is visible in both large-scale wind projects and solar mini-grids, though there is not much evidence of community involvement in wind mini-grid projects, and in the case of large-scale solar, the users tend to be large industrial and/or government players. In large-scale wind projects, the role of national policy makers and governmental agencies has been notable through their direct negotiations with project developers over power purchasing agreements.

\section{Differences and similarities between institutions}

In terms of the institutional dimension of the SISs examined here, there are clear similarities in terms of the role of feed-in tariffs and power purchasing agreements in the large-scale solar and wind projects, while small-scale projects in both the wind and solar sectors are influenced most clearly by state and donor support for hybridisation of the existing diesel-fired mini-grids. What is noticeable, however, is that, despite the same overarching driver existing for the hybridisation of minigrids because of the increasing operational costs of diesel-driven mini-grids, the solar mini-grid segment differs markedly in terms of actors and networks and has received more attention from international donors than wind mini-grids. A number of donor programmes and national plans also mainly support the development of hybrid wind-diesel mini-grids. However, compared to the support for solar-powered mini-grids, the development of wind-powered mini-grids seems to be somewhat under-prioritised in these initiatives. In a number of locations, especially in the eastern and northern parts of Kenya (such as the area surrounding Lake Turkana), which have particularly favourable wind resources, the development of wind-powered mini-grids can become economically viable, although optimising location also depends on local demand (GIZ, 2014). 
Overall, the solar mini-grid market appears to have a more enabling environment that has led to the establishment of a commercial market for the sale of electricity services to rural communities. This private-sector approach to the provision of rural electrification via mini-grids seems to be unprecedented in Kenya and East Africa. Many of the active companies have been started by foreign expatriates with significant expertise in business start-ups, engineering, RE consultancy, telecommunications, and donor organisations. These companies have therefore brought a high level of technical and organisational expertise and management systems into Kenya, which has been combined with knowledge on energy use and needs in local communities collected by the companies over time (Rolffs et al., 2015).

However, across both wind- and solar-powered mini-grids, the challenge remains of the lack of a regulatory framework for the development of commercial mini-grids. Bilateral negotiations between the companies and key government agencies related to obtaining operational licences and approvals of end-user tariffs have shown to be challenging and lengthy (ESMAP, 2016). The prolonged negotiating process is partly related to the different objectives of government agencies and private operators. The commercial tariff proposed by the private companies is significantly higher than the universal tariff offered by the government through the conventional grid-extension programmes to support rural electrification. The regulatory authorities are generally hesitant in accepting the inclusion of private operators that are operating with business models based on low connection fees and high usage rates. In general, one aspect of the difficulties in attracting funding for RE projects is the unclear policy signals and ongoing discussions concerning the possible introduction of new incentive structures and regulatory models. Since the feed-in tariff system was revised in 2012 to its current form, a number of alternative models, such as an auction system, and a net metering system for smaller grid-connected projects, have been discussed. However, solar and wind power projects in various stages of development have been suspended in recent years due to a 'freeze' by Kenya Power and Lighting Company (KPLC) on signing new power purchase agreements.

\section{Concluding remarks: sub-sectoral pathways and policy implications}

In this chapter, we have aimed to analyse and understand innovation dynamics within and between various sub-sectors. Based on the SIS perspective adopted in this chapter there are not only profound differences between solar and wind technologies, but equally importantly differences within these technologies. Overall, the SIS perspective shows that, in terms of the key system dimensions, there is a greater similarity between large-scale wind and solar projects (size), than between projects within the same technologies (shape). The large-scale projects are characterised by scientific knowledge bases (R\&D), with actors with EPC experience or turnkey contracting playing a large role. The projects are 
capital-intensive, involve management expertise and PPA negotiations, and generally involve foreign actors in terms of both technology and expertise, as well as investments. The large-scale sectors differ from small-scale wind and solar mini-grids, which are markedly characterised by decentralised electrification efforts and are highly dependent on tariff structures and cross-subsidies. The rural electrification domain is connected to discussions about grid extensions and sees many donor-driven hybridisation efforts (particularly in solar). However, it has also revealed that there are significant differences between the institutional conditions such as regulation and policy frameworks for wind and solar minigrids, with the solar mini-grid SIS being strengthened by a range of drivers that have led to an unprecedented private-sector-driven approach. In contrast, the wind-power mini-grid projects seem to have suffered both from the comparative success of the solar mini-grid market and the apparent under-prioritisation of the sector by actors otherwise engaged in the mini-grid sector.

Our conclusions have important implications for ongoing policy discussions on the role of government in shaping electrification pathways. It supports the opposition to any 'one size fits all' policy incentive in the renewable energy sector - rather, policy -makers should think about how they want to shape electrification pathways across the sizes and shapes outlined here. Tailor-made policies can help shape the dynamics of each sub-sector, and stakeholders and decision-makers should ask themselves which aspects should be enhanced. The SIS perspective highlights how innovation systems are outcomes of interaction and co-evolution of both size and shape, but also across national borders and links to global industry trends. Yet the literature has also pointed out that knowledge created in specific sectors may not be easily acquired and transferred across sectors. Therefore, attention to nurturing each of these distinct sectors, how to set appropriate tariffs and incentives, but also how to establish a broader framework of technical and procedural regulations is required. The variations across sectors and the role of foreign expertise in driving certain sub-sectors also raise questions about building up the necessary capabilities and expertise within the local market. This call for future research to investigate further the 'structure' of sectoral systems and the kinds of policy mechanisms that may influence this. Furthermore, research into how interactions between and the co-evolution of such sub-sectoral innovation systems can help policy makers understand how regulations and incentive mechanisms may influence co-existing and complementary sub-sectoral systems.

\section{Acknowledgements}

The authors thank participants for feedback on the ideas presented in this article at the IREK workshop in Eldoret, Kenya in February 2017. They are also grateful for constructive and insightful comments from three anonymous reviewers. Support for research on which this chapter is based from the Danish Ministry of Foreign Affairs, Grant: DFC 14-09AAU is gratefully acknowledged. 


\section{Notes}

1 Parts of this book chapter draw on Hansen et al. (2018).

2 An example of the continued focus of the grid operator and energy planning agencies in Kenya on grid extensions to promote enhanced access to electricity for the rural population is the so-called 'Last Mile Connectivity Project' (Gichungi, 2011).

\section{References}

Adebowale, B.A., Diyamett, B., Lema, R. and Oyelaran-Oyeyinka, O. (2014) 'Introduction', African Journal of Science, Technology, Innovation and Development, 6(5), pp. v-xi. https://doi.org/10.1080/20421338.2015.1010774

Bergès, B. (2009) 'Case study of the wind-based rural electrification project in Esilanke primary school, Kenya', Wind Engineering, 33(2), pp. 155-174. https://doi.org/10. 1260/030952409789140982

Byrne, R. (2011) Learning Drivers: Rural Electrification Regime Building in Kenya and Tanzania. Doctoral Thesis (DPhil). East Sussex: University of Sussex.

Duby, S. and Engelmeier, T. (2017) The World's Microgrid Lab. Munich: TFE Consulting.

Energy Sector Management Assistance Program (ESMAP) (2016) Current Activities and Challenges to Scaling Up Mini-grids in Kenya. http://documents.worldbank.org/cura ted/en/173201489180103220/Energy-Sector-Management-Assistance-ProgramESMAP-annual-report-2016

Ferrer-Martí, L., Garwood, A., Chiroque, J., Ramirez, B., Marcelo, O., Garfí, M. and Velo, E. (2012) 'Evaluating and comparing three community small-scale wind electrification projects', Renewable and Sustainable Energy Reviews, 16(7), pp. 53795390. https://doi.org/10.1016/j.rser.2012.04.015

Gesellschaft für Internationale Zusammenarbeit (GIZ) (2014) Where shall We Put It? Solar Mini-grid Site Selection Handbook. Bonn, Germany: Deutsche Gesellschaft für Internationale Zusammenarbeit (GIZ).

Gichungi, H. (2011) Progress Report on Use of Renewable Energy in Off-Grid Areas, pp. 24. https://www.climateinvestmentfunds.org/sites/default/files/knowledge-documents /srep_learning_workshop_report_0.pdf

Government of the Republic of Kenya (2007) The Kenya Vision 2030. Nairobi: Government of Kenya.

Hansen, U.E., Pedersen, M.B. and Nygaard, I. (2015) 'Review of solar PV policies, interventions and diffusion in East Africa', Renewable and Sustainable Energy Reviews, 46, pp. 236-248. https://doi.org/10.1016/j.rser.2015.02.046

Hansen, U.E., Gregersen, C., Lema, R., Wandera, F. and Samoita, D. (2018) 'Technological shape and size: A disaggregated perspective on sectoral innovation systems in renewable electrification', Energy Research and Social Science, 42, pp. 13-22. https://doi.org/10.1016/j.erss.2018.02.012

Harries, M. (1997) 'Disseminating windpumps in rural Kenya: Meeting rural water needs using locally manufactured windpumps', Energy Policy, 30, pp. 1-18. https://doi. org/10.1016/S0301-4215(02)00060-5

Harrington, K. (2016) 'New smart solar microgrids speed up rural electrification in Kenya'. [Online]. Available at: http://www.aiche.org/chenected/2016/02/new-sm art-solar-microgrids-speed-rural-electrification-kenya (Accessed: 06/072020).

IREK (2018) 'Innovation and renewable electrification in Kenya'. AAU/ACTS/ Moi University [Online]. Available at: https://www.irekproject.net/ (Accessed: 12/01/2018). 
Kingiri, A. and Okemwa, J. (2022) 'Local content and capabilities: Policy processes and stakeholders in Kenya', in Building Innovation Capabilities for Sustainable Industrialisation: Renewable Electrification in Developing Economies. New York: Routledge. https://doi .org/10.4324/9781003054665-11

Lema, R., Iizuka, M. and Walz, R. (2015) 'Introduction to low-carbon innovation and development: Insights and future challenges for research', Innovation and Development, 5, pp. 173-187. https://doi.org/10.1080/2157930X.2015.1065096

Lundvall, B.-A. and Lema R. (2014) 'Growth and structural change in Africa: Development strategies for the learning economy', Sustainable Industrialization in Africa, 6(5), pp. 113-138. https://doi.org/10.1007/978-1-137-56112-1_6

Malerba, F. (2002) 'Sectoral systems of innovation and production', Research Policy, 31(2), pp. 247-264. https://doi.org/10.1016/S0048-7333(01)00139-1

Malerba, F. (2005) 'Sectoral systems of innovation: A framework for linking innovation to the knowledge base, structure and dynamics of sectors', Economics of Innovation and New Technology, 14(1-2), pp. 63-82. https://doi.org/10.1080/1043859042000228688

Malerba, F. and Nelson, R. (2011) 'Learning and catching up in different sectoral systems: Evidence from six industries', Industrial and Corporate Change, 20(6), pp. 1645-1675. https://doi.org/10.1093/icc/dtr062

Ogeya, M.C., Osano, P., Kingiri, A. and Okemwa, J. (2022) 'Challenges and opportunities for the expansion of renewable electrification in Kenya', in Building Innovation Capabilities for Sustainable Industrialisation: Renewable Electrification in Developing Economies. New York: Routledge. https://doi.org/10.4324/9781003054665-3

Pedersen, M.B. (2016) 'Deconstructing the concept of renewable energy-based minigrids for rural electrification in East Africa', Wiley Interdisciplinary Reviews: Energy and Environment, 5, pp. 570-587. https://doi.org/10.1002/wene.205

Rolffs, P., Ockwell, D. and Byrne, R. (2015) 'Beyond technology and finance: Payas-you-go sustainable energy access and theories of social change', Environment and Planning A, 47, pp. 2609-2627. https://doi.org/10.1177/0308518X15615368

Rural Electrification Authority (REA) (2009) Rural Electrification Master Plan: Electrification Action Plan 2009-2013. Nairobi: REA.

Stephan, A., Schmidt, T.S., Bening, C.R. and Hoffmann, V.H. (2017) 'The sectoral configuration of technological innovation systems: Patterns of knowledge development and diffusion in the lithium-ion battery technology in Japan', Research Policy, 46, pp. 709-723. https://doi.org/10.1016/j.respol.2017.01.009

Vanheule, L. (2012) Small Wind Turbines in Kenya: An Analysis with Strategic Niche Management. Master Thesis. Delft, Netherlands: Delft University of Technology. 